\title{
Posttraumatic Stress Disorder and Neuroprogression in Women Following Sexual Assault: Protocol for a Randomized Clinical Trial Evaluating Allostatic Load and Aging Process Acceleration
}

Bruno Messina Coimbra ${ }^{1,2}$, MSc; Mary Yeh ${ }^{1,2}$, MD, MSc; Ana Teresa D'Elia ${ }^{1,2}$, MD; Mariana Rangel Maciel ${ }^{1,2}$, MD, $^{2}$ MSc; Carolina Muniz Carvalho ${ }^{1,3,4}, \mathrm{PhD}$; Ana Carolina Milani ${ }^{1,2}, \mathrm{MD}, \mathrm{PhD}$; Adriana Mozzambani ${ }^{1,2}$, PhD; Mario Juruena $^{5}$, MD, PhD; Sintia Iole Belangero ${ }^{1,3,4}$, PhD; Andrea Parolin Jackowski ${ }^{1,4}$, PhD; Dalva Poyares ${ }^{6}, \mathrm{MD}, \mathrm{PhD}$; Andrea Feijo Mello ${ }^{1,2}, \mathrm{MD}$, PhD; Marcelo Feijo Mello ${ }^{1,2}, \mathrm{MD}, \mathrm{PhD}$

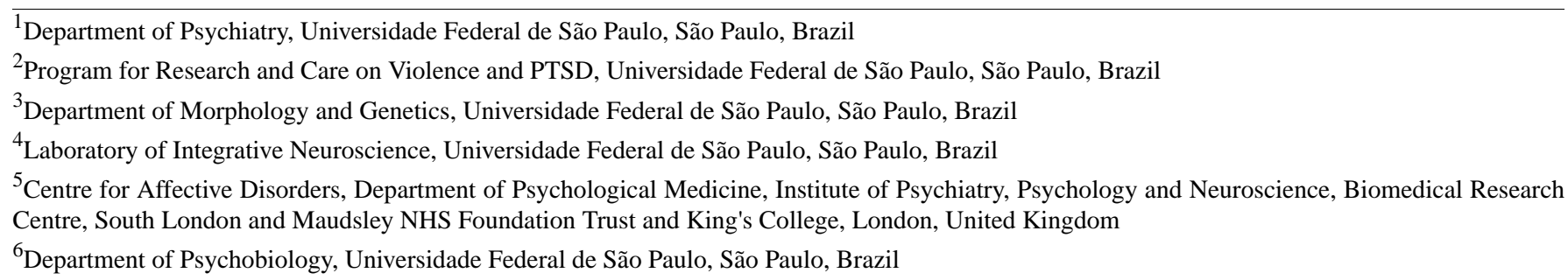

Corresponding Author:

Marcelo Feijo Mello, MD, PhD

Program for Research and Care on Violence and PTSD

Universidade Federal de São Paulo

Rua Major Maragliano 241

São Paulo, 04017030

Brazil

Phone: 551155764990 ext 1064

Email: feijomellom@me.com

\begin{abstract}
Background: Posttraumatic stress disorder (PTSD) is a prevalent, chronic, and severe disorder related to traumatic events. Women are disproportionately affected by PTSD than men and are more at risk in the occurrence of sexual assault victimization. Estimates suggest that $50 \%$ of women develop PTSD following sexual assault and successful clinical management can be challenging. Growing evidence has implicated neural, immune, and endocrine alterations underpinning PTSD, but only few studies have assessed the evolution of acute PTSD in women.

Objective: This study aims to measure whether the onset of PTSD is associated with accelerated aging in women following sexual assault. We hypothesize that the increase of allostatic load caused by PTSD leads to neuroprogression. We will implement a randomized clinical trial to compare responses to treatment with either interpersonal psychotherapy adapted for PTSD (IPT-PTSD) or the selective serotonin reuptake inhibitor sertraline.
\end{abstract}

Methods: We will include women between 18 and 45 years of age, who experienced sexual assault from 1 to 6 months before the initial evaluation, and present with a Diagnostic and Statistical Manual of Mental Disorders, fifth edition (DSM-5) diagnosis of PTSD. Baseline evaluation will comprise clinical and psychometric assessments, structural and functional magnetic resonance imaging, neuropsychological testing, polysomnography, evaluation of immune and endocrine parameters, and genetic analyses. Age-matched female healthy controls will be included and subjected to the same evaluation. Patients will be randomized for treatment in 1 of the 2 arms of the study for 14 weeks; follow-up will continue until 1 year after inclusion via treatment as usual. The researchers will collect clinical and laboratory data during periodic clinical assessments up to 1-year follow-up.

Results: Data collection started in early 2016 and will be completed by the end of the first semester of 2020. Analyses will be performed soon afterward, followed by the elaboration of several articles. Articles will be submitted in early 2021. This research project has obtained a grant from the Fundação de Amparo à Pesquisa do Estado de São Paulo (FAPESP 2014/12559-5).

Conclusions: We expect to provide insight into the consequences of recent sexual assault exposure in women by investigating the degree of neuroprogression developing from an early stage of PTSD. We also expect to provide important evidence on the 
efficacy of a non-exposure psychotherapy (IPT-PTSD) to mitigate PTSD symptoms in recently sexually assaulted women. Further, we aim to obtain evidence on how treatment outcomes are associated with neuroprogression measures.

Trial Registration: Brazilian Clinical Trials Registry RBR-3z474z; http://www.ensaiosclinicos.gov.br/rg/RBR-3z474z/ International Registered Report Identifier (IRRID)： DERR1-10.2196/19162

(JMIR Res Protoc 2020;9(11):e19162) doi: 10.2196/19162

\section{KEYWORDS}

PTSD; neuroprogression; allostatic load; sexual assault; trauma; thematic research; randomized clinical trial; aging

\section{Introduction}

\section{Background}

Posttraumatic stress disorder (PTSD) is a psychiatric disorder triggered by an external traumatic event that exposes a person to an imminent life-threatening situation [1]. PTSD is characterized by intrusive memories and thoughts about the traumatic event, avoidance of trauma-related reminders and feelings, negative alterations in cognition and mood, and hyperarousal [2]. Although trauma is a necessary condition for PTSD diagnosis, not all traumatized individuals will develop the disorder [3]. Those who develop PTSD may show elevated risk of health decline (eg, diabetes, cardiovascular disease, autoimmune diseases, hypertension, and dementia) and comorbidity with other psychiatric disorders [4,5]. PTSD is a significant societal burden, with increased likelihood of hospitalization, suicide, drug abuse, and aggressive behavior [6-8].

PTSD etiology is complex and is underpinned by the integration of endogenous and environmental factors. Molecular genetics-based heritability and epigenetic influences associated with adversities during childhood reflect this integration $[9,10]$. Women are more likely than men to develop PTSD following trauma in a female-to-male ratio of approximately $2: 1[11,12]$ Women also have more prolonged and poorer PTSD outcomes than men regardless of threat or injury event-related factors [13]. The reasons for this gender discrepancy remain unclear, but evidence suggests that psychosocial, cultural, and biological factors play significant roles in the increased vulnerability of women to disorder onset and progression [14,15]. Among traumatic events that may challenge individuals in their lifetime, sexual trauma appears a major instigator of developing PTSD. Approximately half of women will develop PTSD following sexual assault [16].

\section{Allostatic Load and Neuroprogression in PTSD}

PTSD has evolved its concepts in the Diagnostic and Statistical Manual of Mental Disorders, fifth edition (DSM-5) to include a complex heterogeneity of symptom profiles that may impede successful clinical management [17,18]. Despite decades of research, there remains a lack of consensus on the optimal treatment of this disorder [19]. Some guidelines recommend psychotherapeutic and drug-based interventions; however, remission and relapses persist, often leading to chronicity $[20,21]$. This is particularly concerning, as an estimated $50 \%$ of PTSD cases followed up in long-term studies evolve to chronicity $[22,23]$. The concept that "time heals wounds" only holds true for a limited number of individuals with PTSD, which strengthens the notion that important biological abnormalities predate the traumatic event and predispose to disorder severity [24].

The occurrence of trauma leading to PTSD and elevated stress may cause deviations in homeostasis, leading to pathogenic biological alterations. Persistent stress triggers an adaptive response termed "allostasis," in which the organism attempts to cope and restore homeostatic balance through hormonal and physical dynamic changes [25]. However, allostasis is insufficient to explain the consequences of stress in an organism. The term "allostatic load" was thus coined to define the costs of chronic stress exposure associated with elevated or oscillating biological responses [26]. The "costs" of allostatic load are reflected in numerous alterations in endocrinal and immune reactivity, neural circuitry dysregulation, and molecular and physiological deterioration described in the PTSD literature [27].

As stress and challenges involved in PTSD may accumulate allostatic load in the organism and cause dysregulation of biological systems, it is crucial to investigate parameters of neuroprogression in individuals affected by the disorder. Neuroprogression, a term initially developed to describe impairment and neuroanatomical alterations in patients with bipolar disorder, is defined as a pathological brain reorganization that occurs concomitant with the decline in clinical health over the course of the disease, typically reflecting patterns consistent with accelerated biological aging [28]. As previously mentioned, substantial evidence supports the association of PTSD with adverse health outcomes. Only recently has PTSD begun to be more closely linked to biological markers of accelerated aging via measurement of telomere shortening [29] and DNA methylation [30], and in analyses of inflammation [31] and immune responses [32].

\section{Objectives}

We designed a thematic research project to evaluate whether the traumatic events and onset of PTSD are associated with accelerated aging in individuals in the early stages of PTSD who are not chronically ill (medically and psychiatrically). We aim to enroll women in the study to better understand the effects of PTSD in this sex, given the high prevalence and severity of PTSD following sexual violence against women.

At baseline we will compare data from the PTSD group with a healthy non-PTSD control group of women with no sexual trauma history. We hypothesize that the toxicity of the increased allostatic load caused by PTSD symptoms leads to 
neuroprogression, even if the onset of PTSD is recent (less than 6 months). We hypothesize that we will observe:

- Poor treatment outcomes associated with neuroprogression measures.

- Reduced corpus callosum, hippocampus, and anterior cingulate cortex volume associated with increased allostatic load, suggesting that neuroprogression occurs in the early stages of PTSD.

- Alterations in telomere length and in methylation profile of long interspersed nuclear element-1 (LINE-1) regions.

- Downregulation of gene expression.

- Worse sleep quality, reduced rapid eye movement (REM) sleep, and alterations in the heart rate variability during sleep.

- Impairment of executive functions, memory, and attention associated with PTSD severity and negative outcomes.

- Hypothalamic-pituitary-adrenal imbalance, with unregulated cortisol and adrenocorticotrophic hormone levels.

- Persistent inflammatory response with increased levels of inflammatory markers.

Further, we aim to implement a randomized clinical trial (RCT) to compare 2 therapeutic interventions: interpersonal psychotherapy adapted for PTSD versus sertraline. In comparing the 2 interventions, we aim to verify whether treatment response is associated with neuroprogression measures.

\section{Methods}

\section{Overall Study Design}

The thematic research project has a cross-sectional and longitudinal study design with multiple time-point assessments. Hospital Pérola Byington (HPB), the largest public health center facility in São Paulo that offers gynecological care for women following sexual assault, will refer all women eligible to participate in the research. Sexually assaulted women admitted to HPB will initially be requested by HPB staff to complete the National Stressful Events Survey Short Scale for PTSD-Short Scale (NSESSS-PTSD), a brief self-report PTSD screening scale. The Universidade Federal de São Paulo (Federal University of São Paulo) (UNIFESP) team will contact women by telephone to assess initial eligibility criteria. Medical records at HPB will be assessed. An appointment for screening with trained psychologists and psychiatrists at UNIFESP will be scheduled. If eligibility is confirmed, participants will be requested to undergo the following procedures: (1) structural and functional magnetic resonance imaging (MRI); (2) neuropsychological testing; (3) in-laboratory polysomnography; (4) saliva and blood sample collection for inflammatory and immune marker analyses; (5) blood sample collection for genetic analyses. After completing these procedures, all women will be randomized to receive intervention (either ITP-PTSD or sertraline) in a 14-week RCT. At the end of the 14-week RCT, women will undergo treatment as usual. After completing 1 year of treatment in the project, patients will be invited to repeat all baseline procedures, that is, the examinations and testing 1-5 described above (1-year follow-up; Figure 1).

Figure 1. Research process flowchart. IPT: interpersonal psychotherapy; PROVE-UNIFESP: Service for Research and Care on Violence and PTSD; PTSD: posttraumatic stress disorder; RCT: randomized clinical trial; TAU: treatment as usual; UNIFESP: Universidade Federal de São Paulo (Federal University of São Paulo).

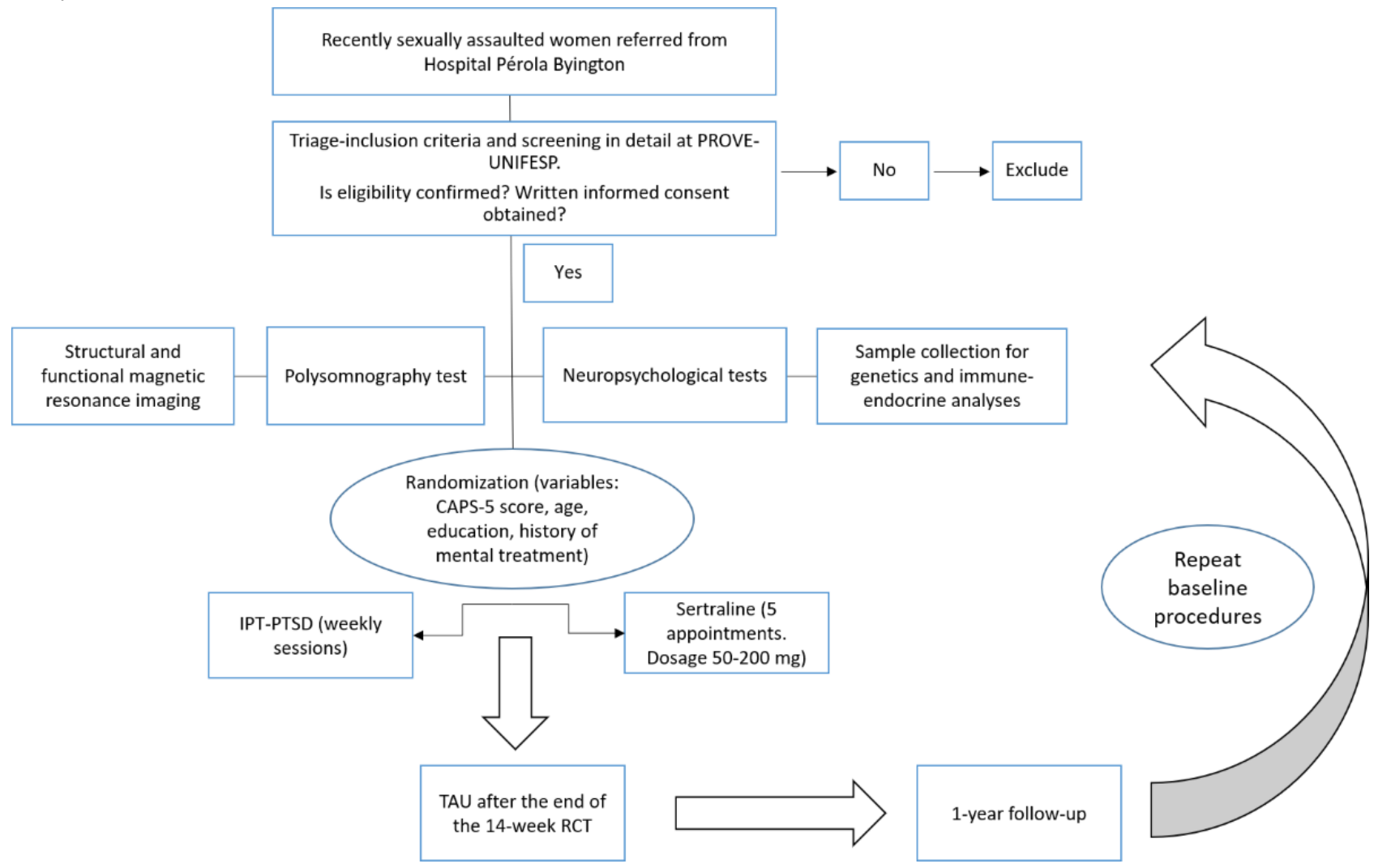


The thematic research project has obtained a 5-year grant from the Fundação de Amparo à Pesquisa do Estado de São Paulo (FAPESP 2014/12559-5). The research will be conducted at the Service for Research and Care on Violence and PTSD (PROVE-UNIFESP) in the Department of Psychiatry at Escola Paulista de Medicina, UNIFESP. It will rely on the cooperation of different UNIFESP departments: the RCT and screening will occur at PROVE-UNIFESP; MRI will be conducted in the Department of Diagnosis in Neuroimaging; saliva and blood sample collection for genetic and inflammatory investigations, as well as the neuropsychological testing, will occur at the Associação Fundo de Incentivo à Pesquisa (AFIP-UNIFESP). The Department of Morphology and Genetics will perform DNA extraction and all genetic analyses. The Instituto do Sono-AFIP will perform in-laboratory polysomnography testing.

\section{Participants}

\section{Patient Recruitment}

We estimate inclusion of 100 patients and 100 matched healthy controls who fulfill inclusion criteria. All participants must sign an informed consent form approved by the UNIFESP Committee Board, in compliance with the Code of Ethics of the World Medical Association (Declaration of Helsinki). Participation in the study will be voluntary without financial compensation. Participants will be compensated only for their public transportation expenses. If at any point in this research, any participant experiences severe symptomatic worsening, or no longer wishes to participate in the study, we will offer immediate standard treatment in our outpatient service.

\section{Inclusion Criteria}

Eligible women are those 18-45 years old with a definite diagnosis for PTSD according to DSM-5, who experienced nonpartner sexual violence between 1 and 6 months prior to study inclusion and developed PTSD following this particular traumatic event. We conceptualized sexual assault as rape (through force or threat), attempted rape, and drug-facilitated rape. Comorbidity with major depression, anxiety disorders, and borderline personality disorder will not be considered exclusion criteria.

\section{Exclusion Criteria}

Women excluded from study participation are those outside the study age range. Further exclusion factors are infection with HIV or other sexually transmissible diseases, acute clinical illness, unstable medical condition, neurological disorders, schizophrenia, bipolar disorder, current use of corticosteroid medication, menopausal symptoms, and substance abuse or dependence not in remission for the last 6 months. We will carefully select patients who are not undergoing any psychological/psychiatric treatment or taking psychotropic medication. Pregnant women will be excluded from the study.

\section{Selection of Healthy Controls}

We intend to enroll 100 female age-matched healthy controls selected from the community with no PTSD and no history of sexual assault who voluntarily comply with study participation. Educational level and socioeconomic characteristics will be taken into consideration to match the PTSD group. All controls will be assessed for eligibility at PROVE-UNIFESP and will undergo the same baseline procedures as the PTSD group: that is, psychometric assessments, MRI, neuropsychological testing, polysomnography, evaluation of immune and endocrinal parameters, and genetic analyses. We will exclude controls diagnosed with psychiatric disorders, currently using psychotropic medication(s), or undergoing psychotherapy. Controls will not undergo treatment and will not be followed up. Controls must not have familial relation to enrolled study patients. The same exclusion criteria for patients will be applied to controls.

\section{Measures \\ Full Sociodemographic Inventory and History of the Sexual Assault Episode}

We developed a detailed sociodemographic inventory to collect relevant sociodemographic characteristics of our participants. We aim to collect the following data on the sexual violence episode: (1) type of violence (rape, attempted rape, or drug-facilitated rape); (2) whether the perpetrator(s) was (were) known (family member, friend, or acquaintance) or unknown; (3) location of the assault (eg, home, public place, working place), precise date, and time of the assault; (4) whether the victim chose to notify the police authorities, and if so, whether an investigation is ongoing; and (5) detailed description of the assault. We will also monitor whether participants adhere to gynecological treatment offered at HPB.

\section{Clinician-Administered PTSD Scale for DSM-5 (CAPS-5)}

This assessment is the gold standard to assess PTSD diagnostic status and symptom severity. The clinician administers this instrument as a structured interview, comprising 30 items assessing both the frequency and the intensity of PTSD symptoms and trauma-associated variables using a frequency/severity scale varying from 0 (never/not severe at all) to 4 (most of the time/severe). Based on a large-scale psychometric study, its authors state that the Clinician-Administered PTSD Scale for DSM-5 (CAPS-5) presented substantial evidence of both its validity and reliability as a measure for PTSD symptoms; it has been adapted to Brazilian Portuguese [33,34].

\section{Mini International Neuropsychiatric Interview (MINI)}

This structured diagnostic interview is designed for clinical practice and research in psychiatric and primary care settings. The Mini International Neuropsychiatric Interview (MINI) provides accurate psychiatric diagnoses (psychosis, mood, anxiety, personality, and PTSD) and is widely used in international psychiatry [35].

\section{Beck Depression Inventory (BDI)}

This self-report instrument is a 21-item questionnaire measuring clinical depression. Each of the 21 multiple-choice questions presents 4 alternatives varying in level of depressive severity (minimal, mild, moderate, and severe). The score consists of the sum of the most severe alternative chosen for each question [36,37]. 


\section{Beck Anxiety Inventory (BAI)}

This 21-item self-report inventory assesses anxiety symptoms. Patients must evaluate how much each anxiety symptom applies to their condition on a severity scale from 0 to 3 . The score sums the individual items, classifying the severity of anxiety as minimum, mild, moderate, or severe [38].

\section{Childhood Trauma Questionnaire (CTQ)}

This self-report instrument for adults and adolescents investigates 5 early stage abuse and negligence experiences. It investigates physical, emotional, and sexual abuse, as well as physical and emotional neglect in childhood. The respondent indicates, on a 5-point Likert scale, the frequency of 28 different childhood situations [39].

\section{Peritraumatic Dissociative Experiences Questionnaire (PDEQ)}

This is a 10 -item measure of dissociative symptoms experienced during or immediately after a traumatic event. The self-rated Peritraumatic Dissociative Experiences Questionnaire (PDEQ) uses a 5-point Likert scale from 1 (not at all true) to 5 (extremely true) [40].

\section{The Clinical Global Impression-Severity Scale (CGI-S) and Clinical Global Impression-Improvement Scale (CGI-I)}

These 7-point scales reflect the clinician's evaluation. The GCI-S requires the clinician to rate the severity of the patient's mental illness based on the clinician's experience with patients with the same diagnosis. Patients are assessed for disease severity rated from 1 (normal) to 7 (extremely ill). The GCI-I requires the clinician to assess how much the patient's condition has improved or worsened relative to the baseline of the intervention. It is rated from 1 (very much improved) to 7 (very much worse) [41].

\section{PTSD Checklist for DSM-5 (PCL-5)}

This 5-point Likert scale is a 20-item self-report assessing the 20 DSM-5 PTSD symptoms. Responses vary according to how much each symptom of PTSD has bothered the individual in the last 4 weeks, rated from 0 (not at all) to 4 (extremely) [42].

\section{Life Event Checklist for DSM-5 (LEC-5)}

This self-report measure assesses the occurrence of traumatic events in an individual's lifetime. The Life Event Checklist for DSM-5 (LEC-5) assesses exposure to 16 events that may potentially lead to PTSD. An additional item encompasses a further extremely stressful event not captured by the other 16 items. The LEC-5 yields no total score and lacks a recognized interpretation protocol, but the instrument is commonly used in combination with other measures, such as the CAPS-5 or PTSD Checklist for DSM-5 (PCL-5), to establish actual occurrence of DSM-5 criterion A traumatic events [43].

\section{Tonic Immobility Scale (TIS)}

This self-report instrument was originally designed specifically to evaluate the presence and severity of tonic immobility in sexually assaulted women. The Tonic Immobility Scale (TIS) reflects physiological and behavioral features that accompany tonic immobility during the traumatic event and comprises 2 parts. The first part assesses multiple dimensional tonic immobility responses; the second assesses victim behaviors in contextual assault circumstances [44].

\section{Structured Clinical Interview for DSM-5 for the Diagnosis of Borderline Personality Disorder (SCID-5)}

This is a semistructured interview administered by the clinician or a trained mental health professional to assess the major DSM-5 diagnoses and symptom severity dimensions of both current and lifetime occurrence of mental disorders [45]. Specific segments for borderline personality disorder, common comorbidity with PTSD, and influential aspects of PTSD treatment outcomes will be used.

\section{World Health Organization's Quality of Life Assessment (WHOQOL-BREF)}

This abbreviated self-rated questionnaire, designed with international cooperation for global cross-cultural use, assesses quality of life. Its 25 facets are scored in environmental, social, physical, and psychological domains [46].

\section{The Revised Adult Attachment Scale (RAAS)}

This 5-point Likert scale measures adult attachment and assesses close interpersonal relationships. The 18 items range from 1 (not at all characteristic) to 5 (very characteristic of me) and are classified into 3 subscales: closeness, dependency, and anxiety [47].

\section{The Sheehan Disability Scale (SDS)}

This brief 3-item self-report measures the impairment and disruption caused by symptoms to work, family, and social functioning. Patients self-rate on a scale from 0 (not at all) to 10 (extremely) [48].

\section{Modified Fatigue Impact Scale (MFIS)}

This 21-item scale assesses the perceived effects of fatigue on quality of life in physical, cognitive, and psychosocial domains. It is mainly used in patients with chronic diseases. The Modified Fatigue Impact Scale (MFIS) uses a 5-point Likert scoring system from 0 (never) to 4 (almost always) [49].

\section{Pittsburgh Sleep Quality Index (PSQI)}

This self-administered, reliable tool evaluates sleep quality and possible disturbances in the previous month. It is used in both clinical practice and research. The 19 Pittsburgh Sleep Quality Index (PSQI) individual items generate 7 component scores: subjective sleep quality, sleep latency, sleep duration, habitual sleep efficiency, sleep disturbances, use of sleeping medication, and daytime dysfunction [50]. We will use an addendum of the PSQI designed explicitly to measure PTSD-related sleep dysfunction [51].

\section{Epworth Sleepiness Scale (ESS)}

This self-report questionnaire measures the occurrence and intensity of daytime sleepiness. The Epworth Sleepiness Scale (ESS) evaluates the probability of falling asleep in 8 situations involving daily activities. Total score ranges from 0 to 24 ; scores over 10 suggest excessive daytime sleepiness [52]. 


\section{Insomnia Severity Index (ISI)}

This brief self-report instrument measures patient perception of his or her insomnia. The Insomnia Severity Index (ISI) targets the subjective symptoms and consequences of insomnia. The ISI also measures the degree of concerns or distress caused by those difficulties. The ISI comprises 7 items assessing the severity of sleep-onset and sleep maintenance difficulties, satisfaction with current sleep patterns, interference with daily functioning, noticeability of impairments attributed to sleep problems, and degree of distress or concern caused by the sleep problems. Each item is rated on a scale from 0 to 4 , and the total score ranges from 0 to 28 [53].

\section{Alcohol Use Disorders Identification Test (AUDIT)}

This 10-item questionnaire was developed by the World Health Organization to identify patients with recent heavy drinking or alcohol dependence. The Alcohol Use Disorders Identification Test (AUDIT) score ranges from 0 to 40. An AUDIT score of 8 indicates a pattern of harmful alcohol consumption; 16 to 19 indicates alcohol abuse, and 20 shows probable dependence [54].

\section{Alcohol, Smoking, and Substance Involvement Screening Test (ASSIST)}

This interview developed by the World Health Organization identifies history and current (past 3 months) use of substances. The Alcohol, Smoking, and Substance Involvement Screening Test (ASSIST) assesses cannabis, cocaine, amphetamine-type stimulants, inhalants, sedatives, hallucinogens, opioids, other miscellaneous drugs, and alcohol or tobacco use. After responding regarding the lifetime use of all substances investigated, participants respond regarding recent use on a 5-point scale (frequency) ranging from "never" to "daily or almost daily" [55].

\section{Detailed Procedures}

\section{Magnetic Resonance Imaging}

Brain MRI scans will be performed using a 3T Philips Achieva scanner with a 32-channel head coil. The MRI protocol consists of a localizer; coronal T2; volumetric T1 (repetition time [TR] $=2000 \mathrm{~ms}$; echo time $[\mathrm{TE}]=3 \mathrm{~ms}$; inversion time $=1100 \mathrm{~ms}$; field of view $=240 \times 240 \times 180 \mathrm{~mm}^{3} ;$ matrix size $=240 \times 240$ $\times 180$ ); axial fluid-attenuated inversion recovery; diffusion tensor imaging (weighted images acquired using a single-shot, spin-echo, echo - planar imaging with $b=1000 \mathrm{~s} / \mathrm{mm}^{2}$ with 31 uniformly distributed, noncolinear direction images, plus 1 additional image acquired with nondiffusion weighting $[b=0$ $\left.\left.\mathrm{s} / \mathrm{mm}^{2}\right]\right) ; 2 \mathrm{D}$ multislice gradient echo sequence with magnitude and phase images $(\mathrm{TR}=500 \mathrm{~ms}, \mathrm{TE}=2.0$ and $4.3 \mathrm{~ms}$; flip angle $=30^{\circ}$, fat saturation $=$ off, water fat shift $=0.3$ pixels, bandwidth $(\mathrm{BW})=1446.8 \mathrm{~Hz} /$ pixel); resting-state functional MRI (isotropic resolution $3 \times 3 \times 3 \mathrm{~mm}^{3}, \mathrm{TR}=2 \mathrm{~s}, \mathrm{TE}=30 \mathrm{~ms}, 300$ volumes); and 3 MRI spectroscopy sequences: (1) in the anterior cingulate gyrus using chemical shift imaging (multivoxel spectroscopy) with a 2D PRESS sequence $(\mathrm{TE} / \mathrm{TR}=45 / 2000 \mathrm{~ms}, 1024$ samples, $\mathrm{BW}=2 \mathrm{kHz}$, voxel size $=10 \times 10 \times 15 \mathrm{~mm}$, matrix $=$ $8 \times 8$ voxels, oversampled to $13 \times 12$ to avoid aliasing, average $=1$, total scan time $=3: 30 \mathrm{~min}) ;(2)$ multiecho single-voxel
PRESS $(\mathrm{TR}=2000, \mathrm{TE}=30,40,50,60, \ldots, 250,260 \mathrm{~ms}[24$ TEs in total], 2048 samples, $\mathrm{BW}=2 \mathrm{kHz}$, voxel size $=20 \times 20$ $\times 20 \mathrm{~mm}$, average $=8$, total scan time $=8: 48 \mathrm{~min}$ ) according to a protocol by Hurd and colleagues [56]; and (3) conventional long TE single-voxel PRESS $(\mathrm{TE} / \mathrm{TR}=144 / 2000 \mathrm{~ms}, 2048$ samples, $\mathrm{BW}=2 \mathrm{kHz}$, voxel size $=20 \times 20 \times 20 \mathrm{~mm}$ with the same positioning as that in [2], average $=96$, total scan time $=$ 3:48 min). All MRI protocols include the acquisition of an unsuppressed water reference spectrum. Details on imaging preprocessing and analyses will be provided in specific studies from this cohort.

\section{Neuropsychological Testing}

Application of a neuropsychological battery will be composed of the following subtests: Wechsler Abbreviated Scale of Intelligence (WASI) Vocabulary and Matrix Reasoning, Digit Subtests of the Wechsler Adult Intelligence Scale (WAIS-III), Rey Auditory Verbal Learning Test (RAVLT), Spatial Span Subtest of the Wechsler Memory Scale (WMS), III Edition, abbreviated version of the Wisconsin Test, Concentrated Attention Test (D2), Prospective Memory Subtest of the NEUPSILIN Scale, Five-Digit Test, and the Stroop Test (Trenerry's version).

\section{Polysomnography}

Participants will undergo 1 night of polysomnography recording in the Instituto do Sono-AFIP at UNIFESP. Recordings will be conducted using Embla N7000 (Embla Systems, Inc.). In the polysomnography test, we will measure brain activity using electroencephalogram electrodes, monitor eye movements using electrooculography electrodes, measure muscle tone using electromyography electrodes, measure heartbeat using electrocardiograph electrodes, and monitor rate of respiration using respiratory monitors. The following sleep variables will be determined: REM sleep latency; sleep onset latency; total sleep time; wake after sleep onset; sleep efficiency; percentages of total sleep composed of N1, N2, N3, and REM sleep; arousal index; number of arousals per hour; periodic limb movements in sleep indices with and without arousal; number of limb movements per hour with and without arousal; apnea-hypopnea index; number of apneas and hypopneas per hour; and REM sleep density. A power spectral analysis of heart rate variability will be performed from the electrocardiogram signal collected throughout sleep and will assess the quantitative contribution of high frequency $(0.15-0.4 \mathrm{~Hz})$, low frequency $(0.04-0.15 \mathrm{~Hz})$, and very low frequency $(0.003-0.04 \mathrm{~Hz})$ components to the total variance.

\section{Immune and Endocrinal Parameters}

Results for interleukin-6, interleukin 1- $\beta$, monocyte chemoattractant protein-1, tumor necrosis factor- $\alpha$, and C-reactive protein will be obtained from blood samples of the participants at the AFIP-UNIFESP at 7:00 am after the polysomnographic examination. We will use ethylenediaminetetraacetic acid (EDTA) tubes, and the plasma will be stored at $-20^{\circ} \mathrm{C}$.

Salivary cortisol samples will be collected using the Salivette kit with a synthetic swab. All participants will be provided instructions according to the kit protocol. Saliva will be collected 
at home 4 times: at 10 p.m. before sleeping and the next day at 6:30 a.m., 7 a.m., and 7:30 a.m.

A second collection of salivary cortisol will be performed at the Instituto do Sono-AFIP at UNIFESP. Professionals will collect saliva at 10 p.m. (prepolysomnographic examination), 6:30 a.m., 7 a.m., and 7:30 a.m. (postpolysomnographic examination).

For C-reactive protein, adrenocorticotrophic hormone, vasopressin, aldosterone, and cortisol analyses, we will use a high-sensitive enzyme-linked immunosorbent assay kit (ELISA). The MILLIPLEX MAP panel based on the Luminex xMAP technology will be used to obtain cytokine results.

\section{Genetics}

Peripheral blood of the participants will be collected in 2 EDTA tubes for DNA isolation and 2 PAXgene RNA tubes for RNA analysis. DNA and RNA extraction will be performed using Gentra Puregene (Qiagen) and PAXgene blood RNA isolation kits, respectively, according to the manufacturer's instructions.

The DNA samples will be used to perform different genetic/epigenetic analyses such as genotyping, measurement of telomere length, and methylation profile over LINE-1 regions. The genotyping of individuals will be performed using the Infinium Global Screening Array BeadChip (Illumina) with approximately 640,000 markers, including rare, common variants, and exonic, intronic, nonsense, missense, indel markers. Telomere length will be measured by quantitative polymerase chain reaction, according to a protocol previously described by Cawthon [57], which consists of determining the relative ratio between the telomere region copy number (T) and a single-copy gene ( $\mathrm{S}-$ albumin gene) using a relative standard curve. The methylation profile of LINE-1 transposable elements was verified by quantification of global methylation of these fragments using polymerase chain reaction followed by sequencing using Pyrosequencing technology.

The RNA samples will be used to investigate the blood transcriptome by sequencing using the NextSeq 500/550 High Output Kit (version 2.5; Illumina).

\section{Randomized Clinical Trial: Interpersonal Psychotherapy Adapted for PTSD Versus Sertraline}

We designed a 14-week RCT comparing IPT adapted for PTSD to sertraline. Our plan is to evaluate the relative efficacy of both interventions, comparing treatment outcome, patient adherence, and tolerability for women in the early stages of PTSD following sexual trauma. Sertraline is a widely used, usually well-tolerated selective serotonin reuptake inhibitor (SSRI) effective as an antidepressant and anxiolytic, and one of the 2 SSRIs FDA approved to treat PTSD [58,59]. However, several guidelines consider antidepressants to be of secondary importance to psychotherapy for the treatment of PTSD [60], and many SSRI-treated patients do not achieve remission [61].

Interpersonal psychotherapy adapted for PTSD is a non-exposure, nontrauma-focused brief therapy designed to minimize the high attrition rates observed in patients undergoing exposure therapies. Many traumatized individuals refuse or are unable to tolerate treatments such as prolonged exposure, as they require facing reminders of the traumatic event(s), which often trigger fear, avoidance, and intolerable stress [62]. The aversive aspects of exposing patients to their traumatic memories and cues may elevate attrition, reducing treatment efficacy. Interpersonal psychotherapy adapted for PTSD explores interpersonal and commonly severe social aftereffects of trauma, not the trauma itself [63]. In one RCT, interpersonal psychotherapy adapted for PTSD produced superior results to prolonged exposure in treatment retention and symptom improvement in chronic sexual assault survivors [64].

Interpersonal psychotherapy adapted for PTSD is delivered in 3 phases: (1) assessment of PTSD diagnosis and patients' interpersonal context, including meaningful past and present relationships. The therapist offers a life crisis formulation that provides the therapeutic focus (2-3 sessions); (2) the therapist helps patients to resolve the focus, eliciting and validating patients' thoughts and feelings and encouraging them to take appropriate social risks to improve abilities to assert wishes and needs in relationships (8-9 sessions); (3) the therapist terminates treatment, calling attention to patients' gains during the process, and reinforces positive roles (eg, as a survivor rather than a victim). Positive and painful aspects of the intervention are addressed to help patients finalize the psychotherapy process (3 sessions) $[63,65]$. Part of adapting IPT for PTSD involves helping numbed patients attune to their emotions, and to recognize them not as dangerous but as helpful interpersonal signals.

In the pre-enrollment consent process, patients will be told about the study design, and that they may not choose between the treatments. Both arms will have a 14-week duration and will be conducted entirely at PROVE-UNIFESP. Patients nonresponsive to treatment will not be crossed over to the other arm, and will be excluded from the research if they become suicidal or if their symptoms become more severe. A brief description of the methods applied in both arms is as follows:

- Interpersonal psychotherapy adapted for PTSD will comprise weekly 50-minute sessions with an experienced, well-trained therapist who will be supervised every week by 2 expert interpersonal psychotherapy adapted for PTSD therapists. The sessions will be audiotaped with patient consent, and the interpersonal psychotherapy adapted for PTSD team will study the recordings to assess therapy quality by rating therapist verbalizations rather than patient responses. Patients will be seen briefly 5 times during the 14-week treatment by a psychiatrist, who will have the option to introduce low dosage of the following sedative medications: quetiapine (25-50 mg), risperidone (1-2 mg), or zolpidem CR (12.5 mg). Interpersonal psychotherapy adapted for PTSD therapists and clinicians will maintain confidentiality.

- Sertraline will be administered using an initial dosage of $50 \mathrm{mg}$ that may be increased to $200 \mathrm{mg}$ over the 14-week treatment. Patients will be seen 5 times during the 14-week trial by psychiatrists experienced in treating patients with PTSD. Additional dosages of quetiapine (25-50 mg), risperidone (1-2 $\mathrm{mg}$ ), or zolpidem CR (12.5 mg) may be used. 
Different psychiatrists will evaluate the patients in either arm of the trial. The additional drugs mentioned above (quetiapine, risperidone, and zolpidem CR) will be prescribed only if patients exhibit high levels of anxiety, fear, or severe insomnia.

The clinical assessments of the study are presented in Figure 2. Longitudinal assessments will occur at week 2 (CGI-S and CGI-I), week 4 (CAPS-5, Beck Depression Inventory [BDI], Beck Anxiety Inventory [BAI], CGI-S, and CGI-I), week 8
(CAPS-5, BDI, BAI, The Revised Adult Attachment Scale [RAAS], CGI-S, and CGI-I), and week 14 (CAPS-5, BDI, BAI, RAAS, WHOQOL-BREF, MFIS, PSQI, SDS, ESS, AUDIT, CGI-S, and CGI-I). The CGI-S and the CGI-I will be used by the clinicians in all appointments. The research team will administer the other scales in a separate meeting with patients. Assessors will be blind to treatment condition and will not provide any treatment. The same measures will be repeated at 1-year follow-up with the addition of the ASSIST.

Figure 2. Clinical assessment flowchart. ASSIST: Alcohol, Smoking and Substance Involvement Screening Test; AUDIT: Alcohol Use Disorders Identification Test; BAI: Beck Anxiety Inventory; BDI: Beck Depression Inventory; CAPS-5: The Clinician-Administered PTSD Scale for DSM-5; CGI-I: The Clinical Global Impression-Improvement Scale; CGI-S: The Clinical Global Impression-Severity Scale; CTQ: Childhood Trauma Questionnaire; ESS: Epworth Sleepiness Scale; IPT: interpersonal psychotherapy; LEC-5: Life Event Checklist for DSM-5; MINI: Mini International Neuropsychiatric Interview; MFIS: Modified Fatigue Impact Scale; PCL-5: PTSD Checklist for DSM-5; PDEQ: Peritraumatic Dissociative Experiences Questionnaire; PROVE-UNIFESP: Service for Research and Care on Violence and PTSD; PSQI: Pittsburgh Sleep Quality Index; PTSD: posttraumatic stress disorder; RAAS: The Revised Adult Attachment Scale; RCT: randomized clinical trial; SDS: The Sheehan Disability Scale; TAU: treatment as usual; TIS: Tonic Immobility Scale; WHOQOL-BREF: World Health Organization's Quality of Life Assessment.

Screening in detail at PROVE-UNIFESP. Sociodemographic inventory. Scales: CAPS-5, BDI, BAI, RAAS, WHOQOL-BREF, MFIS, PSQI, SDS, ESS, ISI, AUDIT, ASSIST, LEC-5, PCL-5, MINI, CTQ, PDEQ, TIS.

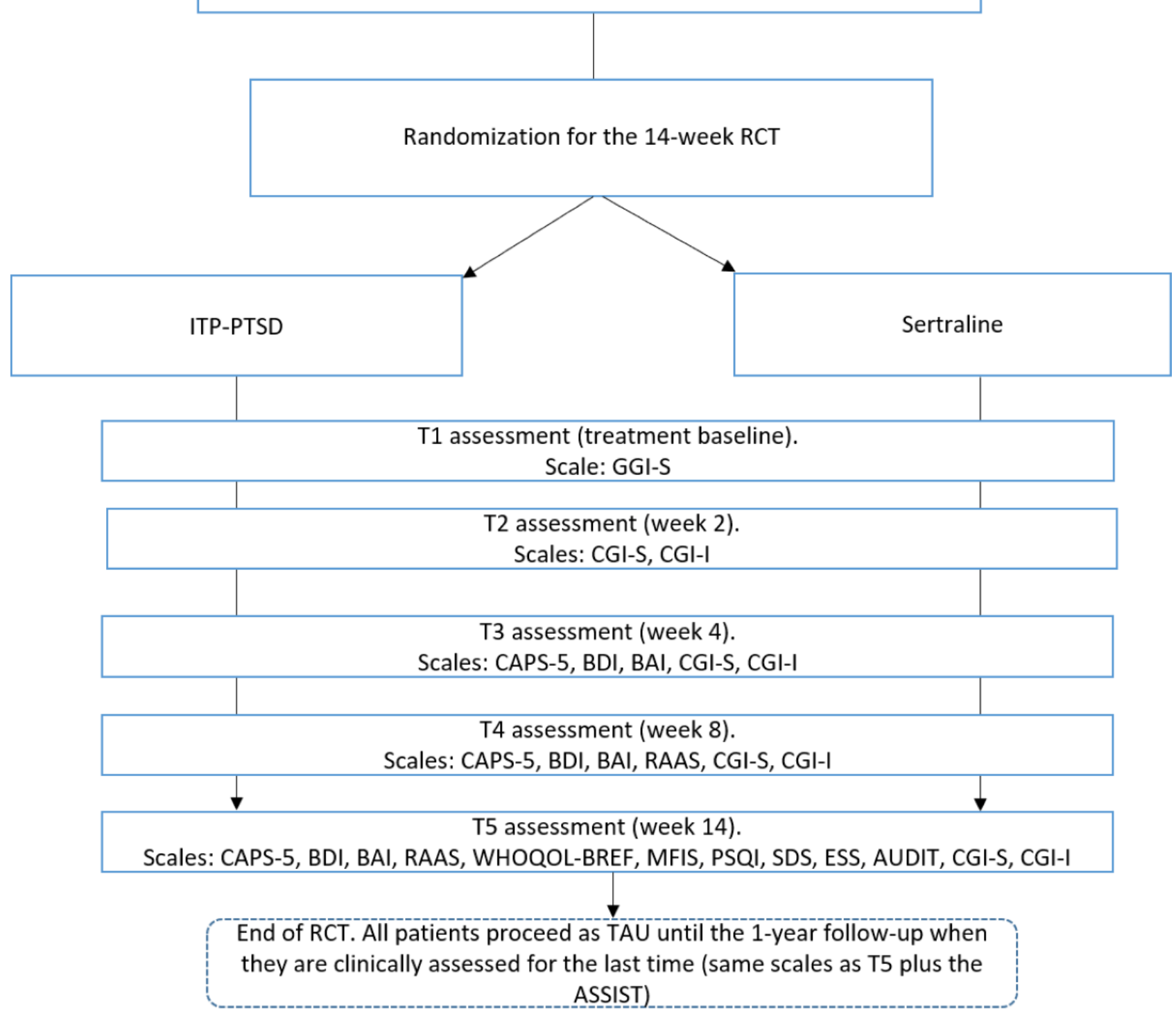




\section{Sample Size Power Calculation for the RCT and Randomization}

A sample size of 84 patients with PTSD (42 in each group) could be adequate considering a difference between 2 independent proportions. To obtain the sample size, we fixed a probability of a type I error of .05 (level of significance), and the power of the test of 0.8 (probability of type II error of .2) for a bicaudal test. In addition, we considered an index of 0.6 $(60 \%)$ of response for active treatment for PTSD, and a placebo effect of $0.3(30 \%)$. We increased the number by $20 \%$ in anticipating dropouts $(\mathrm{n}=102)$ and we will use sequential randomization to prevent an imbalance between treatment groups for known factors (symptom severity, age, educational level, history of previous treatment) that influence prognosis or treatment responsiveness. The sequential randomization also prevents type I error and improves the power of the test for small trials (<400 patients).

We will randomize eligible patients to either interpersonal psychotherapy adapted for PTSD or sertraline using a method developed to balance prognostic factors in psychiatric clinical trials [66]. This method allows allocation into 2 homogenous groups. Randomization will be performed by an independent statistician who will generate an allocation sequence and will keep the assignment schedule in a separate computer. The following variables will be used: CAPS-5 total score, age, educational level, and whether there is history of prior psychological/psychiatric treatment.

\section{Statistical Analyses Planned for the RCT}

We will use a generalized estimating equation [67] to evaluate the effects of time and group randomization (ie, sertraline or interpersonal psychotherapy adapted for PTSD) on 4 different outcomes: CAPS-5 score, BDI, BAI, and CGI-I. Each patient in the RCT will receive 4 time-point longitudinal assessments. We will apply a first-order autoregressive effect working correlation to consider carryover effects of the PTSD symptoms across time [68]. The first-order autoregressive working correlation matrix will be used to deal with the within-subject effect, as it is expected that measurements taken further apart are less correlated than those taken closer together.

Patient attrition is commonly observed and expected in multiple time-point assessment clinical trials. To minimize the impact of patient dropout, an intention-to-treat analysis must be performed [69]. We will use 2 different techniques to deal with missing data when estimating time and group allocation, which are our main covariates of interest. The first technique will be a full-information maximum likelihood, which is the default estimator (maximum likelihood) to accommodate missingness when doing generalized estimating equation. This approach is important due to the long format of the data set and when (at least) baseline measures are available in the outcome. The second technique is a flexible approach to deal with missing data when implementing clinical trials [70]. It replaces missing data with one or more specific values, to allow statistical analysis that includes all participants and not just those who do not have any missing data. We will run all analyses using SPSS (version 24; IBM).

\section{Ethics Approval and Consent to Participate}

The clinical trial of this study was registered at Brazilian Clinical Trials Registry (registration number RBR-3z474z; registration date: March 24, 2015).

The Institutional Review Board of the UNIFESP approved the study protocol. Written informed consent will be obtained, following statement of compliance with the Code of Ethics of the World Medical Association (Declaration of Helsinki) and the standards of the Review Board and granting agency.

\section{Results}

Data collection started in early 2016 and will be completed by the end of the first semester of 2020. Analyses will be performed soon afterward, followed by the elaboration of several articles. Articles will be submitted in early 2021.

\section{Discussion}

Sexual violence against women is a great concern to society and among health providers. It often leads to prolonged and severe mental health consequences such as PTSD. Most studies of the associations between PTSD and neuroprogression evaluate alterations in chronic patients, particularly older male veterans. More research is warranted to investigate the neurobiology of recent PTSD in women. With this thematic research project, we will investigate the occurrence of accelerated biological aging in our patients by assessing markers associated with aging through neuroimaging, genetics, neuropsychological testing, sleep disturbances, immune and inflammatory alterations, and how they relate to clinical outcomes and treatment response.

The main study strength is that it addresses important knowledge gaps in understanding the extent to which PTSD triggered by recent exposure to sexual assault affects neuroprogression in young women. To the best of our knowledge, this is the first thematic research to investigate accelerated aging as a consequence of sexual assault-related PTSD in women from a developing country. Sexual assault in Brazil has reached staggering numbers. Although there is a lack of studies to estimate more precisely the prevalence of sexual assault in the Brazilian population, previous evidence pointed to half a million women being sexually assaulted every year [71]. As sexual assault often leads to PTSD, and violence against women is on the rise in many countries, this is a global public health concern.

Another study strength is its investigation of the effectiveness of interpersonal psychotherapy adapted for PTSD, a non-exposure psychotherapy, in a sample of sexually assaulted Brazilian women. As successful treatment of PTSD can be challenging, we expect our contribution will deepen the discussion of treatment options through implementing an RCT contrasting sertraline with interpersonal psychotherapy adapted for PTSD. This is the first RCT to compare IPT to SSRI for PTSD. Following up our research patients will also permit to assess correlations between treatment response and neuroprogression measures.

The study has limitations. As published evidence on biological markers in the early stages of PTSD is lacking, we are unable 
to calculate the sample size to power the eventual biomarker alterations found in our sample. Based on the previous literature on PTSD interventional studies, we can provide a sample size calculation for the RCT, but not for all investigations that will be conducted in the thematic research project. Furthermore, investigation of aging markers in the early stages of PTSD and in a relatively youthful patient sample may prove too early to be detectable. However, it is warranted to investigate whether PTSD following sexual assault may accelerate deterioration of biological health parameters in young women. Our approach may fuel further research to investigate initial biological alterations in patients with PTSD before evolution to chronicity that could be used as biomarkers in the near future. Another limitation is that social stigma may discourage women from seeking mental treatment following sexual assault. Accordingly, refusal to participate in the study may be high and impede achieving the hoped-for quantity of patients we aim to enroll. Another concern is the possible elevated attrition rates, a common problem in the treatment of PTSD. A high attrition rate could limit the performance of the RCT, and weaken the longitudinal analyses of neuroprogression in our sample and its associations with treatment response.

\section{Acknowledgments}

The authors thank the social workers, psychologists, and gynecologists of Hospital Pérola Byington for their enormous contribution to the development of this research. We gratefully acknowledge UNIFESP team members Cecilia Proença, Cecilia Zylberstajn, Bruna Nicoletta, Thauana Oliveira-Watanabe, Nina Valente, Luciana Porto, Thays Mello, Euthymia Prado, Rosaly Braga, Samara Hipolito Nitzsche, Flavia Strumpf, Roberta Constantino, Camila Matsuzaka, Nathalia Balloni, Fernanda Gomes, Tania Camargo, Paula Maria Serafim, Magda Bignotto, Vinicius Calsavara, and Fernando Rodrigues Grecco. We also thank Dr John Markowitz for his contribution to the design of the RCT. The research is sponsored by FAPESP grant number 2014/12559-5. Additional grant support comes from CNPq 303389/2016-8, CNPq 312464/2018-5, and FAPESP 2015/26473-8. This study is financed in part by the Coordenação de Aperfeiçoamento de Pessoal de Nível Superior - Brasil (CAPES) - Finance Code 001. The funders had no role in study design or decision to publish this protocol article.

\section{Conflicts of Interest}

None declared.

\section{References}

1. American Psychiatric Association, DSM-5 Task Force. Diagnostic and Statistical Manual of Mental Disorders, Fifth Edition. Washington, DC: American Psychiatric Association; 2013.

2. Friedman MJ, Resick PA, Bryant RA, Strain J, Horowitz M, Spiegel D. Classification of trauma and stressor-related disorders in DSM-5. Depress Anxiety 2011 Sep 16;28(9):737-749. [doi: 10.1002/da.20845] [Medline: 21681870]

3. Atwoli L, Stein DJ, Koenen KC, McLaughlin KA. Epidemiology of posttraumatic stress disorder. Current Opinion in Psychiatry 2015;28(4):307-311. [doi: 10.1097/yco.0000000000000167]

4. Davidson JRT. Trauma: The Impact of Post-Traumatic Stress Disorder. J Psychopharmacol 2016 Dec 04;14(2_suppl1):S5-S12. [doi: $10.1177 / 02698811000142$ s102]

5. Taft CT, Creech SK, Murphy CM. Anger and aggression in PTSD. Curr Opin Psychol 2017 Apr;14:67-71. [doi: 10.1016/j.copsyc.2016.11.008] [Medline: 28813322]

6. Byers AL, Covinsky KE, Neylan TC, Yaffe K. Chronicity of posttraumatic stress disorder and risk of disability in older persons. JAMA Psychiatry 2014 May 01;71(5):540-546 [FREE Full text] [doi: 10.1001/jamapsychiatry.2014.5] [Medline: $\underline{24647756}]$

7. Brady KT, Killeen TK, Brewerton T, Lucerini S. Comorbidity of psychiatric disorders and posttraumatic stress disorder. J Clin Psychiatry 2000;61 Suppl 7:22-32 [FREE Full text] [Medline: 10795606]

8. Spoont MR, Williams JW, Kehle-Forbes S, Nieuwsma JA, Mann-Wrobel MC, Gross R. Does This Patient Have Posttraumatic Stress Disorder?: Rational Clinical Examination Systematic Review. JAMA 2015 Aug 04;314(5):501-510. [doi: 10.1001/jama.2015.7877] [Medline: 26241601]

9. Sheerin CM, Lind MJ, Bountress KE, Nugent NR, Amstadter AB. The genetics and epigenetics of PTSD: overview, recent advances, and future directions. Curr Opin Psychol 2017 Apr;14:5-11. [doi: 10.1016/j.copsyc.2016.09.003] [Medline: 28813320]

10. Carvalho CM, Coimbra BM, Ota VK, Mello MF, Belangero SI. Single-nucleotide polymorphisms in genes related to the hypothalamic-pituitary-adrenal axis as risk factors for posttraumatic stress disorder. Am J Med Genet B Neuropsychiatr Genet 2017 Oct 07;174(7):671-682. [doi: 10.1002/ajmg.b.32564] [Medline: 28686326]

11. Farhood L, Fares S, Hamady C. PTSD and gender: could gender differences in war trauma types, symptom clusters and risk factors predict gender differences in PTSD prevalence? Arch Womens Ment Health 2018 Dec 25;21(6):725-733. [doi: 10.1007/s00737-018-0849-7] [Medline: 29802463]

12. Frans O, Rimmö PA, Aberg L, Fredrikson M. Trauma exposure and post-traumatic stress disorder in the general population. Acta Psychiatr Scand 2005 Apr;111(4):291-299. [doi: 10.1111/j.1600-0447.2004.00463.x] [Medline: 15740465] 
13. Holbrook TL, Hoyt DB, Stein MB, Sieber WJ. Gender differences in long-term posttraumatic stress disorder outcomes after major trauma: women are at higher risk of adverse outcomes than men. J Trauma 2002 Nov;53(5):882-888. [doi: 10.1097/00005373-200211000-00012] [Medline: 12435938 ]

14. Tolin DF, Foa EB. Sex differences in trauma and posttraumatic stress disorder: a quantitative review of 25 years of research. Psychol Bull 2006 Nov;132(6):959-992. [doi: 10.1037/0033-2909.132.6.959] [Medline: 17073529]

15. Olff M. Sex and gender differences in post-traumatic stress disorder: an update. European Journal of Psychotraumatology 2017 Jul 27;8(sup4):1351204. [doi: 10.1080/20008198.2017.1351204]

16. Luz MP, Coutinho ES, Berger W, Mendlowicz MV, Vilete LM, Mello MF, et al. Conditional risk for posttraumatic stress disorder in an epidemiological study of a Brazilian urban population. J Psychiatr Res 2016 Jan;72:51-57. [doi: 10.1016/j.jpsychires.2015.10.011] [Medline: 26540404]

17. DiMauro J, Carter S, Folk JB, Kashdan TB. A historical review of trauma-related diagnoses to reconsider the heterogeneity of PTSD. J Anxiety Disord 2014 Dec;28(8):774-786. [doi: 10.1016/j.janxdis.2014.09.002] [Medline: 25261838]

18. Galatzer-Levy IR, Bryant RA. 636,120 Ways to Have Posttraumatic Stress Disorder. Perspect Psychol Sci 2013 Nov 04;8(6):651-662. [doi: 10.1177/1745691613504115] [Medline: 26173229]

19. McFarlane AC, Lawrence-Wood E, Van Hooff M, Malhi GS, Yehuda R. The Need to Take a Staging Approach to the Biological Mechanisms of PTSD and its Treatment. Curr Psychiatry Rep 2017 Feb 7;19(2):10. [doi:

10.1007/s11920-017-0761-2] [Medline: 28168596]

20. Davis LL, English BA, Ambrose SM, Petty F. Pharmacotherapy for post-traumatic stress disorder: a comprehensive review. Expert Opinion on Pharmacotherapy 2005 Feb 24;2(10):1583-1595. [doi: 10.1517/14656566.2.10.1583]

21. Steenkamp MM, Litz BT, Hoge CW, Marmar CR. Psychotherapy for Military-Related PTSD. JAMA 2015 Aug 04;314(5):489. [doi: 10.1001/jama.2015.8370]

22. Morina N, Wicherts JM, Lobbrecht J, Priebe S. Remission from post-traumatic stress disorder in adults: a systematic review and meta-analysis of long term outcome studies. Clin Psychol Rev 2014 Apr;34(3):249-255. [doi: 10.1016/j.cpr.2014.03.002] [Medline: 24681171]

23. Pupo MC, Serafim PM, de Mello MF. Health-related quality of life in posttraumatic stress disorder: 4 years follow-up study of individuals exposed to urban violence. Psychiatry Res 2015 Aug 30;228(3):741-745. [doi: 10.1016/j.psychres.2015.05.030] [Medline: 26115841]

24. Pitman RK, Rasmusson AM, Koenen KC, Shin LM, Orr SP, Gilbertson MW, et al. Biological studies of post-traumatic stress disorder. Nat Rev Neurosci 2012 Nov 10;13(11):769-787 [FREE Full text] [doi: 10.1038/nrn3339] [Medline: 23047775]

25. Kudielka B, Kirschbaum C. Stress and health research. In: International Encyclopedia of the Social \& Behavioral Sciences. Amsterdam, The Netherlands: Elsevier; 2001:15170-15175.

26. McEwen BS. Stress and the Individual. Arch Intern Med 1993 Sep 27;153(18):2093. [doi: 10.1001/archinte.1993.00410180039004]

27. Yehuda R, Hoge CW, McFarlane AC, Vermetten E, Lanius RA, Nievergelt CM, et al. Post-traumatic stress disorder. Nat Rev Dis Primers 2015 Oct 08;1(1):15057. [doi: 10.1038/nrdp.2015.57] [Medline: 27189040]

28. Kapczinski NS, Mwangi B, Cassidy RM, Librenza-Garcia D, Bermudez MB, Kauer-Sant'anna M, et al. Neuroprogression and illness trajectories in bipolar disorder. Expert Rev Neurother 2017 Mar;17(3):277-285. [doi: 10.1080/14737175.2017.1240615] [Medline: 27659841]

29. Li X, Wang J, Zhou J, Huang P, Li J. The association between post-traumatic stress disorder and shorter telomere length: A systematic review and meta-analysis. J Affect Disord 2017 Aug 15;218:322-326. [doi: 10.1016/j.jad.2017.03.048] [Medline: 28486180]

30. Wolf EJ, Logue MW, Stoop TB, Schichman SA, Stone A, Sadeh N, et al. Accelerated DNA Methylation Age. Psychosomatic Medicine 2018;80(1):42-48. [doi: 10.1097/psy.0000000000000506]

31. Miller MW, Lin AP, Wolf EJ, Miller DR. Oxidative Stress, Inflammation, and Neuroprogression in Chronic PTSD. Harvard Review of Psychiatry 2018;26:1. [doi: 10.1097/hrp.0000000000000167]

32. Wolf EJ, Morrison FG. Traumatic Stress and Accelerated Cellular Aging: From Epigenetics to Cardiometabolic Disease. Curr Psychiatry Rep 2017 Aug 29;19(10):75 [FREE Full text] [doi: 10.1007/s11920-017-0823-5] [Medline: 28852965]

33. Weathers FW, Bovin MJ, Lee DJ, Sloan DM, Schnurr PP, Kaloupek DG, et al. The Clinician-Administered PTSD Scale for DSM-5 (CAPS-5): Development and initial psychometric evaluation in military veterans. Psychol Assess 2018 Mar;30(3):383-395 [FREE Full text] [doi: 10.1037/pas0000486] [Medline: 28493729]

34. Oliveira-Watanabe TT, Ramos-Lima LF, Santos RC, Mello MF, Mello AF. The Clinician-Administered PTSD Scale (CAPS-5): adaptation to Brazilian Portuguese. Braz J Psychiatry 2019 Feb;41(1):92-93 [FREE Full text] [doi: 10.1590/1516-4446-2018-0136] [Medline: 30758463]

35. Amorim P. Mini International Neuropsychiatric Interview (MINI): validação de entrevista breve para diagnóstico de transtornos mentais. Rev. Bras. Psiquiatr 2000 Sep;22(3):106-115. [doi: 10.1590/s1516-44462000000300003]

36. Gomes-Oliveira MH, Gorenstein C, Lotufo Neto F, Andrade LH, Wang YP. Validation of the Brazilian Portuguese version of the Beck Depression Inventory-II in a community sample. Braz J Psychiatry 2012 Dec;34(4):389-394 [FREE Full text] [doi: 10.1016/j.rbp.2012.03.005] [Medline: 23429809] 
37. Beck AT, Ward CH, Mendelson M, Mock J, Erbaugh J. An inventory for measuring depression. Arch Gen Psychiatry 1961 Jun;4:561-571. [doi: 10.1001/archpsyc.1961.01710120031004] [Medline: 13688369]

38. Beck AT, Epstein N, Brown G, Steer RA. An inventory for measuring clinical anxiety: psychometric properties. J Consult Clin Psychol 1988 Dec;56(6):893-897. [doi: 10.1037//0022-006x.56.6.893] [Medline: 3204199]

39. Grassi-Oliveira R, Stein LM, Pezzi JC. [Translation and content validation of the Childhood Trauma Questionnaire into Portuguese language]. Rev Saude Publica 2006 Apr;40(2):249-255 [FREE Full text] [doi:

10.1590/s0034-89102006000200010] [Medline: 16583035]

40. Fiszman A, Marques C, Berger W, Volchan E, Oliveira LAS, Coutinho ESF, et al. Adaptação transcultural para o português do instrumento Peritraumatic Dissociative Experiences Questionnaire, Versão Auto-Aplicativa. Rev. psiquiatr. Rio Gd. Sul 2005 Aug;27(2):151-158. [doi: 10.1590/s0101-81082005000200005]

41. Busner J, Targum SD. The clinical global impressions scale: applying a research tool in clinical practice. Psychiatry (Edgmont) 2007 Jul;4(7):28-37 [FREE Full text] [Medline: 20526405]

42. Pereira-Lima K, Loureiro SR, Bolsoni LM, Apolinario da Silva TD, Osório FL. Psychometric properties and diagnostic utility of a Brazilian version of the PCL-5 (complete and abbreviated versions). Eur J Psychotraumatol 2019 Mar 25;10(1):1581020 [FREE Full text] [doi: 10.1080/20008198.2019.1581020] [Medline: 30949301]

43. Lima EDP, Vasconcelos AG, Berger W, Kristensen CH, Nascimento ED, Figueira I, et al. Cross-cultural adaptation of the Posttraumatic Stress Disorder Checklist 5 (PCL-5) and Life Events Checklist 5 (LEC-5) for the Brazilian context. Trends Psychiatry Psychother 2016;38(4):207-215 [FREE Full text] [doi: 10.1590/2237-6089-2015-0074] [Medline: 28076641]

44. Reichenheim M, Souza W, Coutinho ESF, Figueira I, Quintana MI, de Mello MF, et al. Structural validity of the tonic immobility scale in a population exposed to trauma: evidence from two large Brazilian samples. PLoS One 2014 Apr 18;9(4):e94367 [FREE Full text] [doi: 10.1371/journal.pone.0094367] [Medline: 24747437]

45. Shankman SA, Funkhouser CJ, Klein DN, Davila J, Lerner D, Hee D. Reliability and validity of severity dimensions of psychopathology assessed using the Structured Clinical Interview for DSM-5 (SCID). Int J Methods Psychiatr Res 2018 Mar 16;27(1):e1590 [FREE Full text] [doi: 10.1002/mpr.1590] [Medline: 29034525]

46. Fleck MP, Louzada S, Xavier M, Chachamovich E, Vieira G, Santos L, et al. [Application of the Portuguese version of the abbreviated instrument of quality life WHOQOL-bref]. Rev Saude Publica 2000 Apr;34(2):178-183 [FREE Full text] [doi: 10.1590/s0034-89102000000200012] [Medline: 10881154]

47. Collins NL. Working models of attachment: Implications for explanation, emotion, and behavior. Journal of Personality and Social Psychology 1996 Oct;71(4):810-832. [doi: 10.1037//0022-3514.71.4.810] [Medline: $\underline{8888604]}$

48. Leon AC, Olfson M, Portera L, Farber L, Sheehan DV. Assessing psychiatric impairment in primary care with the Sheehan Disability Scale. Int J Psychiatry Med 1997;27(2):93-105. [doi: 10.2190/T8EM-C8YH-373N-1UWD] [Medline: 9565717]

49. Pavan K, Schmidt K, Marangoni B, Mendes MF, Tilbery CP, Lianza S. [Multiple sclerosis: cross-cultural adaptation and validation of the modified fatigue impact scale]. Arq Neuropsiquiatr 2007 Sep;65(3A):669-673 [FREE Full text] [doi: 10.1590/s0004-282x2007000400024] [Medline: 17876412]

50. Bertolazi AN, Fagondes SC, Hoff LS, Dartora EG, Miozzo ICS, de Barba MEF, et al. Validation of the Brazilian Portuguese version of the Pittsburgh Sleep Quality Index. Sleep Med 2011 Jan;12(1):70-75 [FREE Full text] [doi: 10.1016/j.sleep.2010.04.020] [Medline: 21145786]

51. Barbosa Neto JB, Germain A, Mattos PF, Serafim PM, Santos RC, Martini LC, et al. Psychometric properties of the Brazilian version of the Pittsburgh Sleep Quality Index Addendum for PTSD (PSQI-A). Braz J Psychiatry 2014 Apr 15;36(4):330-335 [FREE Full text] [doi: 10.1590/1516-4446-2013-1225] [Medline: 25310204]

52. Bertolazi AN, Fagondes SC, Hoff LS, Pedro VD, Menna Barreto SS, Johns MW. Portuguese-language version of the Epworth sleepiness scale: validation for use in Brazil. J Bras Pneumol 2009 Sep;35(9):877-883 [FREE Full text] [doi: 10.1590/s1806-37132009000900009] [Medline: 19820814]

53. Morin CM. Insomnia: Psychological assessment and management. New York: Guilford Press; 1993.

54. Santos WSD, Gouveia VV, Fernandes DP, Souza SSBD, Grangeiro ASM. Alcohol Use Disorder Identification Test (AUDIT): explorando seus parâmetros psicométricos. J. bras. psiquiatr 2012;61(3):117-123. [doi: 10.1590/S0047-20852012000300001]

55. Henrique IFS, De Micheli D, Lacerda RBD, Lacerda LAD, Formigoni MLODS. [Validation of the Brazilian version of Alcohol, Smoking and Substance Involvement Screening Test (ASSIST)]. Rev Assoc Med Bras (1992) 2004 Apr;50(2):199-206 [FREE Full text] [doi: 10.1590/s0104-42302004000200039] [Medline: 15286871]

56. Hurd R, Sailasuta N, Srinivasan R, Vigneron DB, Pelletier D, Nelson SJ. Measurement of brain glutamate using TE-averaged PRESS at 3T. Magn Reson Med 2004 Mar;51(3):435-440 [FREE Full text] [doi: 10.1002/mrm.20007] [Medline: 15004781]

57. Cawthon RM. Telomere length measurement by a novel monochrome multiplex quantitative PCR method. Nucleic Acids Research 2009 Jan 07;37(3):e21. [doi: 10.1093/nar/gkn1027]

58. Brady K, Pearlstein T, Asnis GM, Baker D, Rothbaum B, Sikes CR, et al. Efficacy and safety of sertraline treatment of posttraumatic stress disorder: a randomized controlled trial. JAMA 2000 Apr 12;283(14):1837-1844. [doi:

10.1001/jama.283.14.1837] [Medline: 10770145]

59. Alexander W. Pharmacotherapy for Post-traumatic Stress Disorder In Combat Veterans: Focus on Antidepressants and Atypical Antipsychotic Agents. P T 2012 Jan;37(1):32-38 [FREE Full text] [Medline: 22346334] 
60. Forbes D, Creamer M, Phelps A, Bryant R, McFarlane A, Devilly GJ, et al. Australian guidelines for the treatment of adults with acute stress disorder and post-traumatic stress disorder. Aust N Z J Psychiatry 2007 Aug;41(8):637-648. [doi: 10.1080/00048670701449161] [Medline: 17620160 ]

61. Berger W, Mendlowicz MV, Marques-Portella C, Kinrys G, Fontenelle LF, Marmar CR, et al. Pharmacologic alternatives to antidepressants in posttraumatic stress disorder: a systematic review. Prog Neuropsychopharmacol Biol Psychiatry 2009 Mar 17;33(2):169-180 [FREE Full text] [doi: 10.1016/j.pnpbp.2008.12.004] [Medline: 19141307]

62. Najavits LM. The problem of dropout from "gold standard" PTSD therapies. F1000Prime Rep 2015 Apr 2;7:43. [doi: $10.12703 / \mathrm{p} 7-43]$

63. Markowitz J. Interpersonal psychotherapy for posttraumatic stress disorder. New York: Oxford Press; 2016.

64. Markowitz JC, Neria Y, Lovell K, Van Meter PE, Petkova E. History of sexual trauma moderates psychotherapy outcome for posttraumatic stress disorder. Depress Anxiety 2017 Aug 04;34(8):692-700 [FREE Full text] [doi: 10.1002/da.22619] [Medline: 28376282]

65. Weissman M, Markowitz J, Klerman G. The Guide to Interpersonal Psychotherapy. New York, NY: Oxford University Press; 2018.

66. Fossaluza V, Diniz JB, Pereira BDB, Miguel EC, Pereira CADB. Sequential allocation to balance prognostic factors in a psychiatric clinical trial. Clinics (São Paulo) 2009 Jun;64(6):511-518 [FREE Full text] [doi:

10.1590/s1807-59322009000600005] [Medline: 19578654]

67. Feng Z, Diehr P, Peterson A, McLerran D. Selected statistical issues in group randomized trials. Annu Rev Public Health 2001 May;22(1):167-187. [doi: 10.1146/annurev.publhealth.22.1.167] [Medline: 11274517]

68. Shults J, Sun W, Tu X, Kim H, Amsterdam J, Hilbe JM, et al. A comparison of several approaches for choosing between working correlation structures in generalized estimating equation analysis of longitudinal binary data. Stat Med 2009 Aug 15;28(18):2338-2355. [doi: 10.1002/sim.3622] [Medline: 19472307]

69. Sylvestre Y. CONSORT: missing missing data guidelines, the effects on HTA monograph reporting. Trials 2011;12(Suppl 1):A61. [doi: 10.1186/1745-6215-12-s1-a61]

70. Kenward MG, Carpenter J. Multiple imputation: current perspectives. Stat Methods Med Res 2007 Jun 02;16(3):199-218. [doi: 10.1177/0962280206075304] [Medline: 17621468]

71. Cerqueira D, de Lima S, Bueno S, Neme C, Ferreira H, Coelho D, et al. Atlas da Violência 2018. Brasília, Brazil: Instituto de Pesquisa Econômica Aplicada; 2018. URL: https://www.ipea.gov.br/portal/images/stories/PDFs/relatorio_institucional/ 180604 atlas da violencia 2018.pdf [accessed 2020-11-08]

\section{Abbreviations}

ASSIST: Alcohol, Smoking and Substance Involvement Screening Test

AUDIT: Alcohol Use Disorders Identification Test

BAI: Beck Anxiety Inventory

BDI: Beck Depression Inventory

CAPS-5: The Clinician-Administered PTSD Scale for DSM-5

CGI-I: The Clinical Global Impression-Improvement Scale

CGI-S: The Clinical Global Impression-Severity Scale

CTQ: Childhood Trauma Questionnaire

DSM-5: Diagnostic and Statistical Manual of Mental Disorders, fifth edition

ESS: Epworth Sleepiness Scale

GEE: generalized estimating equation

HPB: Hospital Pérola Byington

ISI: Insomnia Severity Index

LEC-5: Life Event Checklist for DSM-5

LINE-1: long interspersed nuclear element 1

MFIS: Modified Fatigue Impact Scale

MINI: Mini International Neuropsychiatric Interview

MRI: magnetic resonance imaging

NSESSS-PTSD: National Stressful Events Survey Short Scale

PCL-5: PTSD Checklist for DSM-5

PDEQ: Peritraumatic Dissociative Experiences Questionnaire

PROVE-UNIFESP: Service for Research and Care on Violence and PTSD

PSQI: Pittsburgh Sleep Quality Index

PTSD: posttraumatic stress disorder

RAAS: The Revised Adult Attachment Scale

RCT: randomized clinical trial

REM: rapid eye movement 
SDS: The Sheehan Disability Scale

SSRI: selective serotonin reuptake inhibitor

TIS: Tonic Immobility Scale

UNIFESP: Universidade Federal de São Paulo (Federal University of São Paulo)

WHOQOL-BREF: World Health Organization's Quality of Life Assessment

Edited by G Eysenbach; submitted 07.04.20; peer-reviewed by S Mukherjee, B Smith; comments to author 29.06.20; revised version received 20.08.20; accepted 20.10.20; published 18.11 .20

Please cite as:

Coimbra BM, Yeh M, D'Elia AT, Maciel MR, Carvalho CM, Milani AC, Mozzambani A, Juruena M, Belangero SI, Jackowski AP, Poyares D, Mello AF, Mello MF

Posttraumatic Stress Disorder and Neuroprogression in Women Following Sexual Assault: Protocol for a Randomized Clinical Trial

Evaluating Allostatic Load and Aging Process Acceleration

JMIR Res Protoc 2020;9(11):e19162

URL: http://www.researchprotocols.org/2020/11/e19162/

doi: $\underline{10.2196 / 19162}$

PMID: 33206061

(CBruno Messina Coimbra, Mary Yeh, Ana Teresa D'Elia, Mariana Rangel Maciel, Carolina Muniz Carvalho, Ana Carolina Milani, Adriana Mozzambani, Mario Juruena, Sintia Iole Belangero, Andrea Parolin Jackowski, Dalva Poyares, Andrea Feijo Mello, Marcelo Feijo Mello. Originally published in JMIR Research Protocols (http://www.researchprotocols.org), 18.11.2020. This is an open-access article distributed under the terms of the Creative Commons Attribution License (https://creativecommons.org/licenses/by/4.0/), which permits unrestricted use, distribution, and reproduction in any medium, provided the original work, first published in JMIR Research Protocols, is properly cited. The complete bibliographic information, a link to the original publication on http://www.researchprotocols.org, as well as this copyright and license information must be included. 